\title{
Study on the Path of Easy Poverty Alleviation and Relocation to Help Comprehensive Rural Revitalization
}

\author{
Chen Yue ${ }^{1, *}$ \\ ${ }^{1}$ School of Economics and Management, Tianjin Agricultural College, Tianjin, China \\ *2998128647@qq.com
}

\begin{abstract}
Relocation to alleviate poverty is an important measure to improve farmers' living conditions and an important way to achieve leapfrog development for the poor as well as to win the battle against poverty. The comprehensive realization of rural revitalization requires promoting five aspects from industrial revitalization, talent revitalization, cultural revitalization, ecological revitalization and organizational revitalization. This paper combines the requirements of easy poverty alleviation and relocation with the comprehensive realization of rural revitalization, takes the villages in the Yellow River beach area in Shandong Province as an example, and discusses the path of effective connection between industrial revitalization, talent revitalization, cultural revitalization, ecological revitalization, organizational revitalization and easy poverty alleviation and relocation, taking into account the current situation of collective relocation of villagers in the Yellow River beach area.
\end{abstract}

Keywords: Easy poverty alleviation and relocation, Rural revitalization, Yellow River beach area

\section{INTRODUCTION}

On October 29, 2020, the Fifth Plenary Session of the 19th Central Committee of the Communist Party of China officially adopted the proposal on the 14th Five-Year Plan for National Economic and Social Development, proposing the need to prioritize agricultural development and comprehensively promote rural revitalization. The relocation project to alleviate poverty is a special initiative proposed by the Party and the Government to address poverty during the critical period when China is winning the battle to build a moderately prosperous society and achieve the goal of two hundred years of struggle.

Relocation for poverty alleviation refers to the relocation and resettlement of poor people living in areas lacking living conditions to other areas, and helps the relocated population gradually get out of poverty and become rich by improving the production and living conditions in the resettlement areas, adjusting the economic structure and expanding income generation channels. Relocation is an important measure to improve the living conditions of farmers, a fundamental way to achieve leapfrog development of poor people, and an important way to win the battle against poverty, which can fundamentally improve living conditions, and the target of relocation is mainly to face the population living in deep mountains, rocky mountains, drought and flood areas and other areas with poor living environment ${ }^{[1]}$.

The Yellow River beach area is a large area of land that appears within the banks of the lower Yellow River after the flood waters have receded, and has been formed over a long historical period as a large-scale population settlement. The two provinces of Shandong and Henan, which have the largest area of the Yellow River beach area, have 1.895 million residents in the beach area, including about 600,000 people in the Yellow River beach area in Shandong Province. The Yellow River basin in Shandong Province enters from Dongming County, Heze City, Shandong Province, and merges into the Bohai Sea in Kenli District, Dongying City, this part of the river is 628 kilometers long, with a beach area of 1,702 square kilometers, flowing through 29 counties and districts in 9 cities. Due to historical factors, natural environmental factors, and the fact that the lower Yellow River beach area is both an important area for flooding and sedimentation and a place where many rural people live, the villages in the Yellow River beach area are generally characterized by poor public 
infrastructure, low flood resistance, poorly constructed drainage systems and low wind and sand protection.

According to incomplete statistics, since the founding of New China, the Yellow River beach area in Shandong Province has been flooded more than 20 times, affecting a total of 6.6 million people and more than 700,000 hm2 of arable land; the Yellow River beach area in Henan Province has suffered 31 floods of different degrees, affecting a total of 6.1 million people and 1.2 million $\mathrm{hm} 2$ of arable land; the most serious years of flooding in the beach area were 1958 and 1996. The 1958 floods threatened the whole line of embankments on both sides of the Yellow River in Shandong Province, Henan Province, flooding 1,708 villages, involving 740,800 people, flooding 3.04 million mu of arable land, and collapsing and damaging 300,000 houses; in August 1996, the Yellow River flooded 1,438 villages, flooding 174,300 hm2 of arable land, involving 1.15 million people, and collapsing and damaging 540,000 houses. The people in the beach area have been affected by floods repeatedly for years, and they have been worried about the occurrence of floods for a long time, and the phenomenon of returning to poverty due to building houses is prominent, and they strongly hope to break away from the vicious cycle of "saving money for three years, building a platform for three years, building a house for three years, and repaying the debt for three years". The case study was selected because of the high poverty rate in the villages of the Yellow River beach area. According to the characteristics of the Yellow River beach area, through the form of relocation, reasonable measures can be taken to promote the comprehensive revitalization of the villages in the Yellow River beach area, so that relocation is not only a measure to move farmers into buildings, but also a sustainable measure to help villagers achieve higher income levels and increase their sense of well-being.

\section{CURRENT SITUATION AND PROBLEMS OF RELOCATION TO ALLEVIATE POVERTY}

\subsection{Insufficient number of resettlement buildings constructed}

In view of the declining attractiveness of cities to the population in the beach areas, the majority of the older generation of villagers hope that their children can be relocated to their homes because of their attachment to their hometowns and the expectation that their children and grandchildren will live in their homes; some of the new generation of migrant workers who have gone to work plan for themselves to save in the big cities when they are young and strong so that they can return to their hometowns in their middle and old age. The villages in the Yellow River beach area are located in the plain area, with flat terrain and relatively convenient transportation, and are close to the county town or city center. The opening of public transport routes enables the residents of the beach areas to reach the cities quickly and conveniently and to experience urban life, which brings the residents of the beach areas closer to the cities on a psychological level, and the previous eagerness of the rural population to leave the constraints of the land and become an urban population is gradually cooling down ${ }^{[2]}$.

With the full opening of the three-child policy, some young people of childbearing age with a single child in rural areas will choose to have children in due course, while there is a large number of young people of marriageable age, especially men, who need to prepare a house for post-marital residence. These potential population increases are not taken into account in the planning for the construction of relocated buildings in the beach areas, and these villagers are also under pressure to buy houses again.

\subsection{Limitations of the criteria for allocating housing by domicile}

After a study of nine villages in the Mudan District of Heze City, Shandong Province, most of the villages have set standards for the allocation of housing space in new buildings for relocation, stipulating that only residents with household registration in the village at the time of relocation can receive a new village housing unit of 40 square meters per person. Receive a new village housing unit. Compared to villagers who were born, grew up and lived in the village and whose household registration has not changed for a long time, those who have moved out of the village have a higher level of education, more experience in non-agricultural work and a broader perspective that can contribute more to the development of their hometown.

This compensation policy not only restricts foreign talents from choosing the village for development, but also restricts people whose origin is in the village who are currently working or studying away from home from returning to their hometown, especially for university students, whose will to build their hometown is hindered by the fact that they cannot get a resettlement building after returning to their hometown because their household registration is not in their hometown.

\subsection{Relocated buildings are functionally homogeneous and poorly equipped for commercial and non-profit organization use}

Relocation for poverty alleviation refers to the relocation and resettlement of poor people living in areas lacking living conditions to other areas, and helps the relocated population gradually get out of poverty and become rich by improving the production and living 
conditions in the resettlement areas, adjusting the economic structure and expanding the channels for increasing income. Relocation is an important initiative to improve the living conditions of farmers, a fundamental way to achieve leapfrog development for the poor, and an important way to win the battle against poverty, which can fundamentally improve living conditions. The types of buildings constructed for easy relocation in villages in the beach area include only civilian housing and village committee office buildings without extra houses for commercial use or to run non-profit organizations, and from the purpose of adjusting the industrial structure to broaden income channels, villagers operate small and micro businesses, villages develop ecological tourism or handicrafts and light industry without planning land, limiting the productive activities that villagers can engage in to simple agricultural labor.

\subsection{Incomplete public infrastructure development}

In a survey of 23 randomly selected villages in Shandong Province, it was found that 40 per cent of the new relocated village communities included buildings for villagers to live in, office buildings for village committees, public fitness facilities, street lights and asphalt roads, except for some necessary supporting facilities that were not in the construction plan, such as kindergartens, community hospitals, convenience stores, courier receiving points, public activity rooms and other facilities essential to the lives of villagers ${ }^{[3]}$. In addition, the rural population is mainly engaged in agricultural production as the main source of household income, the type of agricultural production includes planting and farming, most of the villagers in the relocated village are engaged in planting for a living, and some of the villagers are also engaged in farming, the large production tools needed for planting such as tractors, harvesters, carts, plows, etc. are nowhere to be placed after the villagers move into the buildings. Some villagers have built fences around the entrance of their flats in order to continue raising these animals, which not only affects the surrounding environment, but also causes inconvenience to the residents of the same flats.

\section{5. egalitarianism in the relocation process is difficult to achieve}

2.5.1. Criteria for the allocation of housing space in relocated new villages do not apply egalitarianism

In the relocation policy for the Yellow River beach area, there is a uniform division standard for all people relocated within the village, that is, compensation for relocated houses is based on whether the household is in the village or not, if the household is in the village, you can get a new village house of 30 or 40 square meters (the area varies from province to province), if there is no household in the village, even if you live in the village for a long time, you cannot get a new village house. If you move your household for work or school, you will not be able to get a new village house if your household is not in the area at the time of moving. This allocation then leads to some villagers with lower income levels, multiple generations of children and grandchildren living together, and no experience of working outside the village, to obtain a new village house with a larger area after this housing allocation; while residents whose original place of residence is large, with sound housing equipment, and houses that cost more to build but are occupied, and whose household registration is not in the village lose their eligibility to obtain a new village house because the occupants have gone out to work or returned home after retirement. Under this form of distribution, some villagers have been able to lead a higher standard of living than their original standard of living as a result of the relocation, while others have seen their standard of living decline as a result of this relocation.

2.5.2 The value of the construction of the original dwelling and all materials included in the original dwelling that cannot be transferred are not subject to averaging

Before relocation, the village government assesses and compensates all village houses, including trees planted in the house, convenient living facilities such as wells constructed, and the area of the house according to the area of the constructed house (the area of buildings other than the courtyard). The criteria for compensation are fixed, for example, the criteria for dividing trees are based on the number of trees only, and the compensation for buildings is based on the area only. However, due to the long history of house construction in the village, there are both adobe houses in disrepair and brick houses repaired later, and the villagers have different income levels and spent different amounts on house construction, but the compensation for demolition and relocation does not cover all the expenses of the villagers on house construction, especially for those who spent more on the construction of their original houses. Therefore, in terms of compensation, whether it is for the construction of the house or the planting of trees inside the house, the villagers who always spend more on the items that cannot be transferred to the new village building feel more unfair in terms of compensation. 
Table 1. Detailed table of problems with easy relocation

\begin{tabular}{|c|c|c|}
\hline \multirow{10}{*}{$\begin{array}{l}\text { Current Situation } \\
\text { and Problems of } \\
\text { Easy Relocation } \\
\text { for Poverty } \\
\text { Alleviation }\end{array}$} & \multirow{2}{*}{$\begin{array}{l}\text { Insufficient number of rehousing } \\
\text { blocks built }\end{array}$} & Declining attractiveness of the city \\
\hline & & Fertility policy changes \\
\hline & \multirow{2}{*}{$\begin{array}{l}\text { Limitations of the criteria for allocating } \\
\text { housing by domicile }\end{array}$} & Difficulty in retaining foreign populations \\
\hline & & Limits the return of local people to their homes \\
\hline & \multirow{2}{*}{$\begin{array}{l}\text { Relocated building with a single } \\
\text { function }\end{array}$} & Commercial housing needs \\
\hline & & Non-profit organisation needs \\
\hline & \multirow{2}{*}{ Poorly developed public infrastructure } & Inadequate basic production facilities \\
\hline & & Inadequate basic amenities \\
\hline & \multirow{2}{*}{$\begin{array}{l}\text { Egalitarianism in the relocation } \\
\text { process is difficult to achieve }\end{array}$} & $\begin{array}{l}\text { No egalitarianism applied to housing size allocation } \\
\text { criteria }\end{array}$ \\
\hline & & $\begin{array}{l}\text { No egalitarianism applied to former housing payout } \\
\text { rates }\end{array}$ \\
\hline
\end{tabular}

\section{STUDY ON THE PATH OF EASY POVERTY ALLEVIATION AND RELOCATION TO PROMOTE COMPREHENSIVE RURAL REVITALIZATION}

\subsection{Promote talent revitalization with easy relocation}

\subsubsection{Widening of household restrictions on the payment of compensation for resettlement buildings}

Changing the policy on compensation for resettlement buildings for easy relocation and widening the household registration restrictions on the compensation for resettlement buildings to attract talented people from outside to return home. After an investigation and study of $\mathrm{H}$ village in Mudan District, Heze City, Shandong Province, it was found that the village's housing area allocation standard for new buildings for easy relocation stipulates that only residents whose household registration is in $\mathrm{H}$ village at the time of relocation can get a new village housing of 40 square meters per person, and those who are relocated for work reasons, school reasons, those who used to work outside $\mathrm{H}$ village and keep their household registration in the work unit area, and those who live in $H$ village for a long time but do not have an $H$ village household registration cannot obtain a new village resettlement building. This compensation policy not only restricts foreign talents from choosing $\mathrm{H}$ village for development, but also restricts those who are currently working or studying outside of $\mathrm{H}$ village from returning to their hometown, especially for university students who cannot get a resettlement house after returning to their hometown because their household registration is not in their hometown, so they have nowhere to live and are discouraged from returning to their hometown. Attracting rural talents to return to the village can provide a continuous impetus for rural development.
Rural development needs to be driven by professional and technical personnel, and rural college students choose to return to their hometowns for development because they love agriculture and care about rural areas.

The number of new village buildings should not be built solely on the basis of completing the resettlement of all villagers; the number of new village buildings should be appropriately increased for the purpose of providing accommodation for the introduction of talents, reserving housing for outgoing persons whose household registration is not in Village $\mathrm{H}$ and who do not currently live in Village $\mathrm{H}$ but have the intention of returning to live there, selling them or developing the service industry ${ }^{[4]}$.

\subsubsection{Implementation of the agricultural science and technology talent support programme}

Governments at all levels are now actively implementing plans to help agricultural talents in science and technology, analysing the strengths and weaknesses affecting local agricultural development, putting forward needs in a planned and purposeful manner, joining with experts in relevant fields and major universities to implement the science and technology missionary system, matching science and technology missionaries with villages and towns in need according to the professional characteristics of the missionaries, and offering advice on technical problems in rural industrial development in poor areas. Bringing together experts in basic research in agricultural science and humanities and social sciences, experts in technical extension, experts in industrial technology system positions, provincial and ministerial-level talents, retired experts and experts from enterprises, and establishing an expert team of the Institute of Science and Technology to support rural revitalization, docking with rural agricultural supply-side reform and rural revitalization's demand for modern agricultural technology, and policy supporting experts to carry out applied technology research and development and the promotion and transformation of technical results. Give full play to the role of high-level talents in the field of agricultural and 
rural research and high-level agricultural science and technology innovation, and build a high-end think tank for rural industrial prosperity research, rural governance mode research and agricultural development policy research that serves rural revitalization government decision-making and policy formulation. Support agricultural talents to go to the countryside and enter villages, build bridges for communication between agricultural talents and farmers, and establish a stable cooperative relationship between talents and local governments. Achieving rural revitalization is not a task that can be accomplished in a short period of time and requires long-term assistance to poor villages, so the construction process of new village buildings for easy relocation should take into account the introduction of talents and the accommodation of experts in various fields.

\subsection{Promoting cultural revitalization through easy relocation}

\subsubsection{Preserve traditional rural culture and avoid allowing it to decline as a result of changing living conditions}

In the planning of the new village building footprint, space is set aside for collective activities of the villagers. Compared to the urban construction of residential buildings, the new village building should leave more space for the villagers to live and work collectively to facilitate the rituals held by the villagers to continue the traditional culture. In rural areas, there are many different rituals from urban areas, such as the New Year period in some areas will be collective New Year worship, the whole village collectively participate in the village temple to pray for blessings, fireworks, set up incense and fire candles; if someone in the village gets married, the village women will take the initiative to gather to sew quilts for the new couple and many other activities, rural culture has always occupied a very important place in the long history of China, traditional culture It does not necessarily have to be replaced with the development of the times, we should also maintain a respectful attitude towards the perception of traditional culture in the countryside, and to protect these traditional cultures and perpetuate them. Use modern means and information channels to spread these cultures so that more people can understand this culture. If each village has a unique traditional culture that has been perpetuated, it is possible to use this collective activity space to publicize this culture by recording videos and uploading them to popular online platforms such as Shake and Share, so that more people can understand these cultures and participate in the activities held in these cultures, forming a unique industrial culture and using this to develop local tourism and increase the collective income of the village.

\subsubsection{Improving public service facilities}

When planning the designation of land use area for housing construction for easy relocation, we should not only focus on the quality and appearance of the relocated buildings, but also devote ourselves to improving the public service facilities in the community of the relocated new village buildings, such as kindergartens, primary schools, community hospitals, fitness facilities, convenience stores, express receiving points, etc., so as to provide convenience for the villagers' daily life and meet their modern living needs. During the investigation of $\mathrm{H}$ village in the Yellow River beach area of Heze City, Shandong Province, it was found that the new village community in $\mathrm{H}$ village included buildings for villagers to live in, office buildings for the village committee, public fitness facilities, street lights and asphalt roads, but some necessary supporting facilities were not included in the construction plan, such as kindergartens, community hospitals, convenience stores, courier receiving points, public activity rooms, and other facilities essential to the life of villagers. In addition, the rural population is mainly engaged in agricultural production as the main source of household income, the type of agricultural production includes planting and farming, most of the villagers in Village $\mathrm{H}$ are engaged in planting for a living, and some villagers are engaged in farming, the large production tools needed for planting such as tractors, harvesters, carts, plows, etc. are not available after the villagers move into the buildings, and the villagers who have cattle, sheep, pigs, chickens, ducks, geese and other poultry and livestock before relocation Some villagers have put up fences outside the entrance of their flats in order to continue to raise these poultry and livestock, which not only affects the surrounding environment, but also causes inconvenience to the residents of the same flats. The relocation of rural areas should take into account the actual situation, not unilaterally pursuing the direction of urban community construction, but to carry out comprehensive, detailed and perfect planning for the relocation community according to the characteristics of agricultural and rural areas.

\subsection{Promoting industrial revitalization through easy relocation}

\subsubsection{Relocated new villages rely on their surroundings to attract urban residents to buy homes}

With the development of the times and the progress of society, people's living standards are constantly improving, and China has developed very rapidly in recent years, and has become the second largest country in terms of gross national product. The main contradiction facing China has changed to the 
contradiction between people's desire for a better life and the unbalanced and insufficient development, and people's desire for a better life has been gradually reflected in their desire for rural life in recent years. People no longer pursue the life in big cities, but start to yearn for a leisurely and relaxed idyllic life, especially many middle-aged people who work in the city hope to live in the countryside after retirement, in view of this, the government of the villages involved in the relocation should take this aspect into consideration, not only to be able to accommodate all the villagers as the quantitative target for the construction of new villages, but also to consider the subsequent development. Before building the new relocation villages, it should be possible to solicit purchase intentions from the general public, keep a record of the number of people interested in buying the new village buildings, and increase the number of buildings built appropriately according to the number of people recorded.

\subsubsection{Promoting the modernization of the agricultural industry}

Cultivate new industries and new business models. As agriculture covers a wide area, involves many objects and is multifunctional, it combines the geological characteristics of the Yellow River beach area, promotes the deep integration of agriculture with leisure tourism, historical and cultural heritage and development, cultural and creative industries, health and wellness industries, and develops sightseeing tourism agriculture, tourist experience agriculture, creative agriculture, etc.

Based on the cultural diversity of the coastal areas of the Yellow River Basin, it is possible to develop diversified agriculture in this way, to realize the regional segmentation of the agricultural industry, to facilitate the support of rural revitalization by segmentation and zoning, to select and cultivate new varieties of high-quality crops, livestock and poultry, and aquatic products with local characteristics that are suitable for the cultivation and breeding conditions of agricultural bases for leisure and tourism tourism, and to jointly develop cultivation and breeding techniques to match them with agricultural experts from various fields.

To provide localities with distinctive processing and manufacturing technologies and infrastructure applicable to the production of local folk crafts, and technologies and equipment for harmless waste treatment applicable to different types of business entities of different scales. Vigorously support the promotion of the development of the rural e-commerce industry, catering services and entertainment industry, develop new technologies for agricultural informatization with special applications around these new industries, and develop technologies for the collection, collation and mining of agricultural and rural big data and cloud platforms. Building bridges for direct links between efficient scientific cultivation techniques, agricultural research results and farmers.

The reform of agricultural industry in the Yellow River Tract should start from the structural reform on the supply side, promote the transformation of scientific research results to drive the ability of industrial development, put the high efficiency breeding of crops, long-term green prevention and control of harmful organisms, efficient use of agricultural resources, quality and safety control of agricultural products, whole genome selection breeding technology of major livestock and poultry, agricultural synthetic biotechnology, agricultural big data integration technology, agricultural nanotechnology, agricultural artificial intelligence technology, the Intelligent equipment development and other research results are displayed, so that scientific and technological research results do not only exist in documents, but also appear on the land and in the farms in a way that is easily accepted by farmers.

It is recommended that special websites and knowledge transfer service points for rural scientific research results be established to systematically display the transformed forms of research results of researchers, and collect and update them according to crop types in different categories, and arrange relevant experts and technicians to explain and guide farmers through the Internet or in the form of face-to-face transfer, so that farmers can learn about them at the first time without leaving their homes and in a convenient and quick manner. Knowledge. The advancement of science and technology in agricultural farming technology should not only stay at the level of scientific research, but also be accepted and practiced by the main agricultural producers before it can be regarded as a real meaningful scientific and technological progress.

\subsection{Promoting ecological revitalization with easy relocation}

\subsubsection{Establishment of wetland parks}

Since 1950, the Yellow River beach area in Shandong Province has suffered more than 20 times from large and small Yellow River floods, with a cumulative population of more than 6.6 million people affected. The Yellow River beach area has large wetland ecological resources, and with the help of relocation, the ecological landscape of the Yellow River beach area can be improved comprehensively, and the ecological functions and functions of ecological functions can be used rationally to maintain the ecological stability and balance of the Yellow River beach area. The establishment of a wetland park can promote the development of local tourism with the advantage of geographical location, and at the same time protect the 
diversity of plant and animal species and genetic diversity in the beach area, which can provide a living environment for endangered wild animals and plants, such as providing habitats for waterfowl, migration, breeding and wintering places, so as to protect them from human activities. As the people in the Yellow River beach area live next to the Yellow River beach area for a long time, the villages are not evenly distributed, and the people also develop and use the surrounding land for farming as much as possible, which intentionally or unintentionally destroys the living space of wild animals and plants, after the relocation, the villages change from the original scattered and large area to a dense and greatly reduced area, and the place where the original villages are located after the relocation can be The relocated villages are located in areas where wetland parks can be established and used for other purposes to increase land use $^{[5]}$.

\subsubsection{Strengthen the cultivation of new varieties of agricultural products in the Yellow River beach area}

Strengthen the cultivation of new varieties adapted to the landscape of the Yellow River beach area, and promote the synergy between agriculture and natural environment improvement. As the landscape contained in the Yellow River mudflats in Shandong Province is not suitable for the cultivation of large agricultural products, in order to improve the yield of crop products in the mudflats, it is necessary to fully remediate the landscape of the Yellow River mudflats to make it change to a state suitable for cultivation, expand the area of land suitable for cultivation to increase land utilization, and avoid the idea that some farmers have little awareness of ecological protection. Relying on the scientific research of crops in various departments, we will make concerted efforts to cultivate new varieties with excellent quality, cold resistance, flood resistance and wide adaptability, and strive to combine the cultivation of crops with the natural environment management of the beach area, use the growth and development characteristics of plants to prevent wind and sand, and use the habits of livestock to produce organic fertilizer using livestock manure to increase the fertility of barren land, etc., so as to achieve the improvement of the natural environment and the cultivation area of agricultural products In addition to increasing the yield of traditional agriculture, developing new varieties and increasing land utilization, we are striving to achieve synergy between agricultural production and natural environment improvement, forming a two-way mutually beneficial agricultural development model ${ }^{[6]}$.

\subsection{Promoting organizational revitalization through easy relocation}

$\begin{array}{llrr}\text { Improving social security } & \text { for } & \text { rural } \\ \text { revitalization.Local governments have } & \text { issued }\end{array}$ programmatic documents on the policy of science and technology support for rural revitalization based on the current situation of local agricultural production and analysis of future development trends, so as to guide the direction of work for each grass-roots government, and to give each grass-roots government and each relevant agricultural business entity and each supporting agricultural organization a program on which to base. Each grass-roots township government sets up a special leadership group responsible for science and technology supporting rural revitalization, formulates development goals, introduces relevant measures, links farmers and science and technology steering groups, coordinates science and technology helping talents, new agricultural business entities, private enterprises and agricultural retail households to jointly participate in the cause of rural revitalization, vigorously publicizes the work of science and technology helping, supervises and supervises the progress of helping, and solves the problems raised by farmers. Be responsible for summarizing and analyzing the results of science and technology support for rural revitalization to realize the sustainable development of rural revitalization work. Strengthen the assessment work of the participating departments, formulate a clear division of responsibilities and inspection and evaluation system, establish a work evaluation index model, include the increase in the number of people out of poverty and the growth rate of farmers' income in the evaluation index system, and implement a reward and punishment system. A system of regular reporting on the results of rural revitalization work and irregular spot checks has been developed, and a third-party evaluation method has been introduced to build a multi-party evaluation mechanism to ensure the implementation of rural revitalization work.

\section{MECHANISM TO DOVETAIL EASY POVERTY ALLEVIATION AND RELOCATION WITH COMPREHENSIVE RURAL REVITALIZATION}

According to the above description, the mechanism of relocating people to alleviate poverty and fully realizing rural revitalization includes the realization methods of talent revitalization, cultural revitalization, industrial revitalization, ecological revitalization and organizational revitalization, the current problems of relocating people to alleviate poverty, and the docking path between the realization methods and the existing problems. 


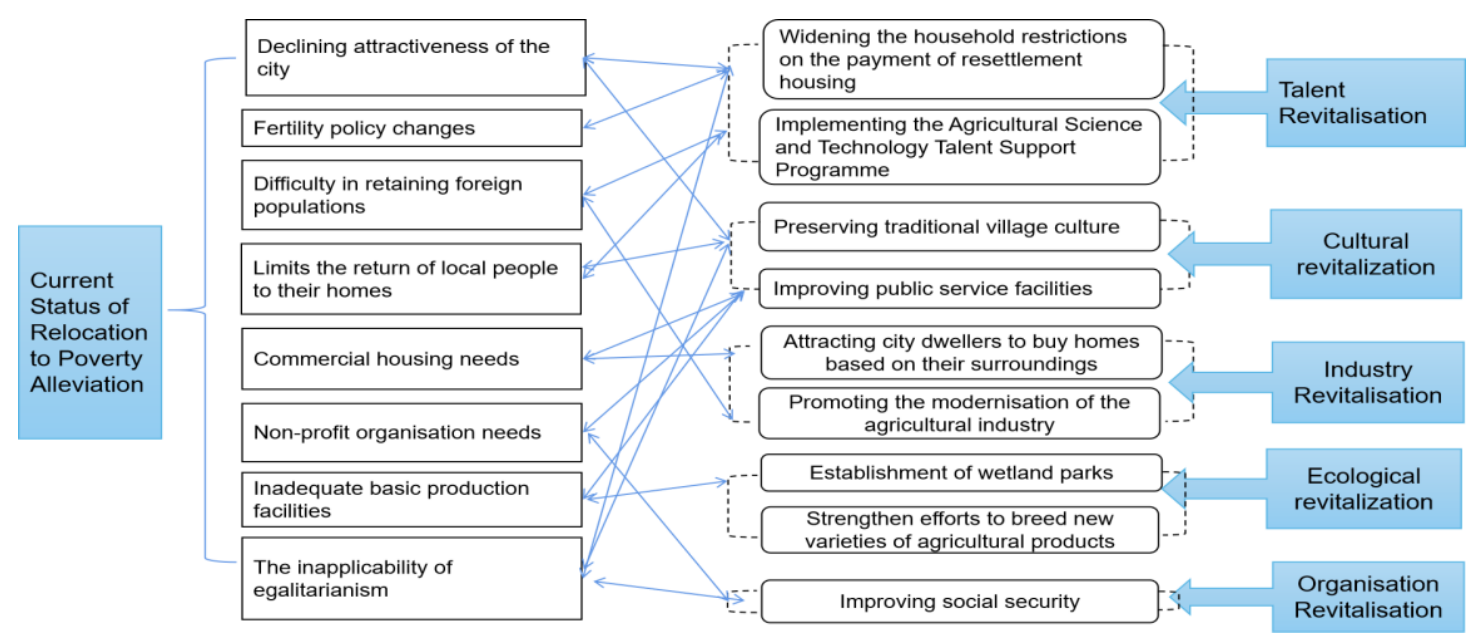

Figure 1.Mechanism to dovetail poverty alleviation and comprehensive rural revitalization

As can be seen from the above diagram, the main methods to realise talent revitalisation are to widen the criteria for household registration and implement a programme to help scientific and technological talents; the main methods to realise cultural revitalisation are to preserve traditional rural culture and improve public service facilities, the methods to realise industrial revitalisation are mainly to rely on the surrounding environment to improve the sales of new village buildings, the main methods to realise ecological revitalisation are to establish ecological parks and increase the cultivation of new varieties of agricultural products, and the methods to realise The main method of organisational revitalisation is to improve social security. The main problems with easy-access relocation are the declining attractiveness of the city, the increased demand for housing due to the three-child birth policy, the difficulty in retaining the foreign population, the restriction on the local population returning to their hometowns, the demand for commercial housing, the demand for non-profit organisations, inadequate infrastructure and the difficulty in achieving egalitarianism $^{[7]}$. The articulated paths between the problems of easy-land relocation and the methods of realizing comprehensive rural revitalization do not correspond one-to-one, but are intricate and complex, and the subjects and objects at the two ends of each path may be duplicated, reflecting the fact that the docking mechanism between easy-land relocation and comprehensive rural revitalization is a comprehensive, integrated and three-dimensional system.

\section{CONCLUTION}

Relocating people from one place to another has greatly improved their sense of well-being and security of residence, effectively benefiting millions of people. However, the willingness of village households to relocate varies depending on the depth of poverty, livelihood type and household characteristics. For example, households in deep poverty due to old age, sickness, disability and fear of high relocation costs are reluctant to relocate or rely on government resettlement. The all-inclusive approach to relocation, the single means of relocation assistance, and the unreasonably quantified monetary subsidies ignore the differences in poverty depth, livelihood characteristics and poverty alleviation needs of the relocated households, which can easily lead to "over" or "under" assistance and breed This can lead to "over" or "under" assistance and "relief dependency", which reduces the precision and effectiveness of relocation and poverty alleviation. Only by following the five paths of rural revitalisation can we truly achieve the goal of relocating the poor, stabilising them and enabling them to get rich.

\section{AUTHORS' CONTRIBUTIONS}

Most of the previous studies on the issue of relocation have been on the evolution of the relocation process, relocation policies, relocation systems, relocation models, relocation settlements and follow-up work. The study aims to improve the livelihoods of rural residents in areas with poor natural conditions and to achieve a comprehensive rural revitalisation. This project will fill the gap in the research on the impact of relocation on the production and livelihood of farmers, enrich the research system on relocation and make the research in this area complete.

By conducting a field survey on the Wen case, collecting and collating information on the impact of relocation on various aspects of local residents' production and life, we can learn how effective relocation is in a specific area, whether the local relocation policy is reasonable, and how to promote rural revitalisation in five areas together, and provide realistic solutions and suggestions for future relocation work and other poverty alleviation measures. 


\section{ACKNOWLEDGMENTS}

This work was supposed by Tianjin Postgraduate Research Innovation Key Projects in 2020(2020YJSS111).

The authors are grateful to Dr.Liu Hong Yin for his help with the preparation of figures in this paper.

\section{REFERENCES}

[1] Li Yang, Qi Guangyong,AND Xiong Kunxin." Research on innovation development in rural revitalization strategy." Journal of Northern University for Nationalities (Philosophy and Social Science Edition) .03 (2019):123-130. doi:CNKI:SUN:XBDR.0.2019-03-019.

[2] He Feiyun, Liu Shunjing,and Chen Xiju." Research and reflection on accelerating the revitalization of rural industries - taking Zengcheng District, Guangzhou City, as an example." Exploration .03 (2020):84-93.

doi:10.13996/j.cnki.taqu.2020.03.010.

[3] Wu, Feng-Hua, and Yu, Chong-Yang." The historical evolution and theoretical logic of easy migration relocation." Journal of Northwestern University (Philosophy and Social Science Edition) $48.05 \quad$ (2018): 112-120. doi:10.16152/j.cnki.xdxbsk.2018-05-012.

[4] Li Fanghai." An empirical study on the satisfaction of the masses in the construction of beautiful countryside - an analysis based on the survey in Liuan City, Anhui Province." Journal of Wanxi College $32.04 \quad$ (2016): 29-33+40. doi:CNKI:SUN:WXXB.0.2016-04-007.

[5] Hu Yisan." Study on the safe construction and compensation policy of the Yellow River beach area." People's Yellow River .05 (2007):1-2+79. doi:CNKI:SUN:RMHH.0.2007-05-000.

[6] Zhang Hui, et al. "Causes and countermeasures of poverty in the Yellow River beach area of Henan Province." Henan Agricultural Science .02 (2010): 110-112.

doi:10.15933/j.cnki.1004-3268.2010.02.037.

[7] Zeng Xiaoxi,AND Wang Sangui." Analysis and reflection on the situation of easy poverty alleviation and relocation." Journal of Henhai University (Philosophy and Social Science Edition) $19.02 \quad$ (2017): 60-66+91. doi:CNKI:SUN:HHZX.0.2017-02-010. 